\author{
(с) Д.В. Юдаков ${ }^{1 *}$, С.П. Бондаренко ${ }^{2}$, А.А. Трухин ${ }^{3}$
}

'Национальный исследовательский ядерный университет «МИФИ», Москва, Россия

Российский национальный исследовательский медицинский университет имени Н.И. Пирогова, Москва, Россия

${ }^{3}$ Национальный медицинский исследовательский центр эндокринологии, Москва, Россия

Леонидас Д. Маринелли является величайшим американским физиком-радиологом итальянского происхождения. Благодаря его стараниям мы имеем представление о влиянии радиации на организм, во врачебной практике появился уникальный метод лечения онкологии щитовидной железы с помощью радиоизотопа I ${ }^{131}$. В статье подробно освещены жизненный путь и становление ученого. Это заслуживает особого внимания читателей, так как Маринелли пришел к успеху благодаря собственному упорству и труду, несмотря на все трудности и препятствия, он получил высшее образование в Америке и обрел наставника в лице доктора Джоаккино Файлла. Именно с ним Леонидас впоследствии стал сотрудничать, реализовал свой потенциал, сделал множество открытий на стыке физики и медицины, являющихся актуальными по сей день. Отдельное внимание в данной работе уделяется двум весомым открытиям Маринелли: это сосуды Маринелли, позволяющие регистрировать гамма-излучение, и формула Маринелли, предназначенная для расчета терапевтической активности I'131. Мы осветили в своей статье различные жизненные этапы и жизненные сферы ученого, постарались максимально доступно разъяснить суть его деятельности.

КЛЮЧЕВЫЕ СЛОВА: Леонидас Д. Маринелли; медицинская физика; радиобиология; ядерная медицина; радиология; эндокринология; история медицины.

\title{
FROM PHYSICS TO MEDICINE, FUNDAMENTALIST LEONIDAS D. MARINELLI
}

(c) Danila V. Yudakov ${ }^{1 *}$, Sofiia P. Bondarenko², Alexey A. Trukhin ${ }^{3}$

${ }^{1}$ National Research Nuclear University MEPhI (Moscow Engineering Physics Institute), Moscow, Russia

2Pirogov Russian National Research Medical University (RSMU), Moscow, Russia

${ }^{3}$ Endocrinology Research Centre, Moscow, Russia

Leonidas D. Marinelli is the greatest Italian-born American radiological physicist. Thanks to his efforts, we have an idea of the effect of radiation on the body; in medical practice a unique treatment for thyroid cancer with the help of the radioisotope $\mathrm{I}^{131}$ has appeared. The article describes in detail the life path and the formation of a scientist, which deserves special attention from readers, since Marinelli came to success thanks to his own perseverance and work, despite all the difficulties and obstacles, he received a higher education in America, found a mentor in the person of Dr. Joachino File, with whom they later became colleagues, realized their potential, made many discoveries at the intersection of physics and medicine, which are relevant to this day. Special attention in this work is paid to two significant discoveries of Marinelli, these are Marinelli's vessels, which allow registering gamma-radiation, and Marinelli's formula, designed to calculate the therapeutic activity of $\mathrm{I}^{131}$. We analyzed all the available materials, selected, highlighted in our article various life stages and life spheres of a scientist, tried to explain the essence of his activities as much as possible.

KEYWORDS: Leonidas D. Marinelli; medical physics; nuclear medicine; radiology; endocrinology.

Леонидас Д. Маринелли - физик-радиолог с итальянскими корнями. Несмотря на то что он не был связан с медициной напрямую, смог воплотить свои идеи на благо медицинского сообщества и укрепить принципы трансляционной медицины. Благодаря его усилиям, жизненному труду и стремлениям мы имеем представление о влиянии радиации на организм, в частности на щитовидную железу, широкие диагностические и терапевтические возможности, огромное количество спасенных жизней не одного поколения, вектор развития медицины и смежных наук.

\section{СТАНОВЛЕНИЕ}

Леонидас Маринелли (рис. 1) родился в семье владельца банка Винченцо Маринелли и Амелии Саммартино Маринелли в Буэнос-Айресе, Аргентина, 28 ноября 1906 г., был старшим сыном среди 6 детей. Ему было 11 лет, когда его отец умер от сердечного приступа. В этот период его жизни он вместе с семьей мигрировал на родину, в Аньоне, Италия, где семья Маринелли основала свой литейный цех еще в XII в. [1]. Леонидас 


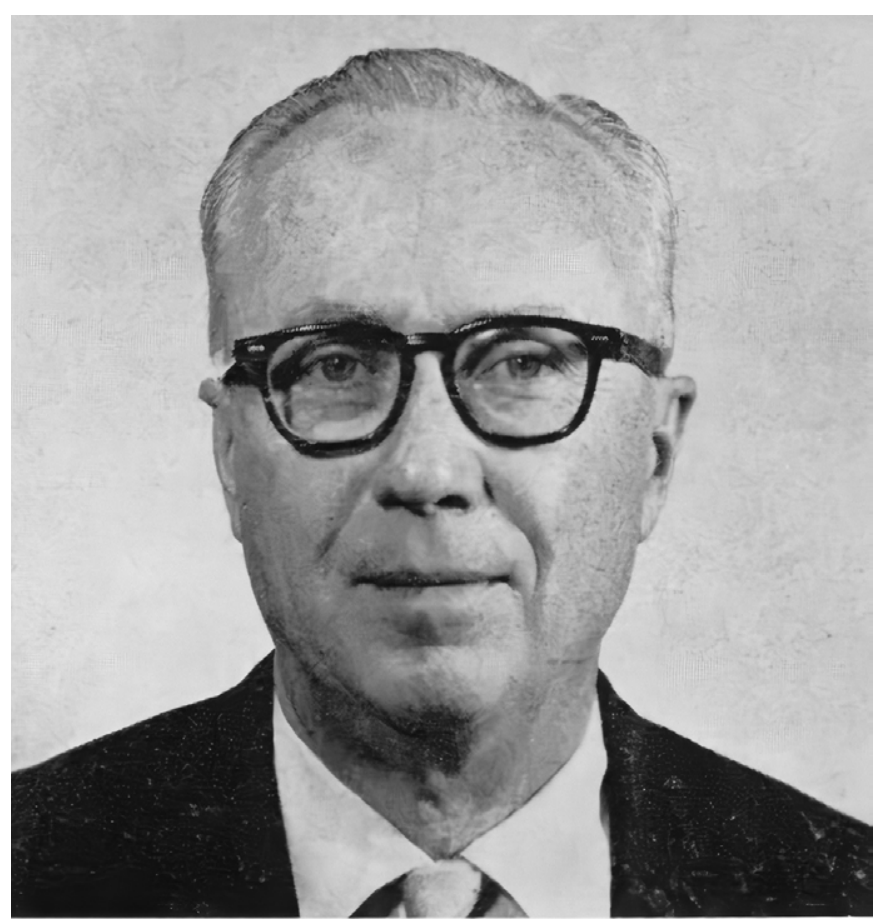

Рисунок 1. Леонидас Д. Маринелли

окончил технический колледж «Институт Вольта» в Неаполе в октябре 1925 г. с отличием и золотой медалью королевы Виктории.

Через 2 месяца после своего 19-летия он эмигрировал в Нью-Йорк и обеспечивал себя, работая лаборантом в вечерней школе электротехники «Купер Юнион». В 1929 г. Джоаккино Файлла, бывший студент Марии Кюри, пригласил Леонидаса в биофизическую лабораторию Мемориальной онкологической больницы в Нью-Йорке, известной сегодня как Мемориальный онкологический центр Слоана Кеттеринга.

Год спустя Леонидас Маринелли измерил интенсивность гамма-излучения радия, ранее не поддающегося количественной оценке, в электростатических единицах, которые были преобразованы в экспозиционную мощность дозы. Это сделало возможным сравнение рентгеновских и гамма-лучей. Ученым был сделан вывод, что рентгеновские лучи имеют большие по значению длины волн, чем гамма-лучи, впоследствии это оказалось полезным для оценки методов оказания медицинской помощи [2].

1930-е годы стали одним из наиболее важных периодов в жизни Маринелли. В это время он начал свою активную деятельность в области радиологии. Он получил степень бакалавра наук в электротехнике в «Купер Юнион» в Нью-Йорке в 1931 г. В 1933 г. Леонидас начал взаимодействовать с Дж. Файлла, Эдит Куимби и Джоном Э. Роузом. Результатом данного сотрудничества является множество совместных открытий. Одним из таких трудов является работа по «Влиянию фильтрации на интенсивности поверхности и глубины рентгена на 200 КэВ». В 1935 г. он стал ассистентом медицинского физика. Затем Леонидас Д. Маринелли сделал ряд публикаций (около 10 работ), сотрудничая с другими известными учеными, такими как Фэрроу Дж. Х. и др.

Степень магистра физики он получил в Колумбийском университете в 1938 г. В этом же году у него было опубли- ковано 5 работ в радиологических журналах, и в 1939 г. он вступил в экспертное сообщество Северной Америки в области радиологии.

В 1940 г. Маринелли стал независимым ученым, начал заниматься научными исследованиями без прямой зависимости от какого-либо научного института или университета. Обязанности директора лаборатории были возложены на него вследствие ухода Дж. Файлла и Э. Куимби из Мемориального онкологического центра [3].

В 1941 г. ученый связал свою деятельность с исследованием постлучевых изменений крови и поиском способов обнаружения раковых клеток на ранних стадиях; в 1942 - с производством хромосомных разрывов в растительных клетках и с теорией временного распределения лучевых обработок. В это же время был совершен методический прорыв в радиойодтерапии: заручившись поддержкой директора больницы Монтефиоре М. Лейтера и в сотрудничестве с медицинским физиком Л.Д. Маринелли из Мемориального центра Слоуна Кеттеринга, доктор Сейдлин заказал наработку терапевтической активности 102 мКи смеси I130/1 131 у профессора Р.Д. Эванса. В марте 1943 г. пациент с метастазами щитовидной железы получил первую лечебную активность радиойода $\left(\mathrm{I}^{130} / \mathrm{I}^{131}\right)$. Используя счетчик Гейгера, С. Сейдлин и его коллеги, в том числе Леонидас Д. Маринелли, смогли показать накопление радиойода в проекции костных метастатических очагов [4].

\section{СОСУДЫ МАРИНЕЛЛИ}

Особое место в его карьере и научной деятельности имеет такое изобретение, как сосуд Маринелли. Немалоизвестные ученые, Р.Ф. Хилл и Г. Дж. Хин, в своем докладе из Института Слоана Кеттеринга писали «Данное оборудование, впервые разработанное Л.Д. Маринелли и используемое в нашей лаборатории с 1943 г., теперь можно приобрести в компании Technical Associates ("Технические партнеры"), Корпорации Глендейла, Калифорния» ${ }^{\mathrm{a}}[5,6]$.

В 1940-1950 гг. основное предназначение стакана Маринелли заключалось в анализе I $^{131}$ в жидкостях (например, в моче). Изначально сосуд Маринелли представлял собой пирексовый лабораторный стакан с выступающей снизу полой трубкой (рис. 2).

Детектор представляет собой обычно стеклянную трубку Гейгера-Мюллера (счётчик Гейгера-Мюллера). Он предназначен для регистрации гамма-излучения. Для проведения измерений счетчик помещается в центральной трубке, а сосуд заполняется изучаемым образцом. Благодаря такой конструкции прибора точность измерений получается довольно высокой [2].

В лабораторных условиях используют стаканы Маринелли различных размеров: для изучения образцов малого объема применяли небольшие сосуды, для образцов большого объема - большие. К сожалению, при увеличении объема путем разбавления образца измерения теряли свою эффективность ${ }^{\mathrm{b}}$.

Hill, R.F., Hine, G.J. and Marinelli, L.D. (February 1950). The Quantitative Determination of Gamma Radiation in Biological Research. American Journal of Roentgenology and Radium therapy: 160.

b Marinelli, L.D. and Hill, R.F. (1948). «Brookhaven National Laboratory Conference Report BNL-C-5»: 98. 


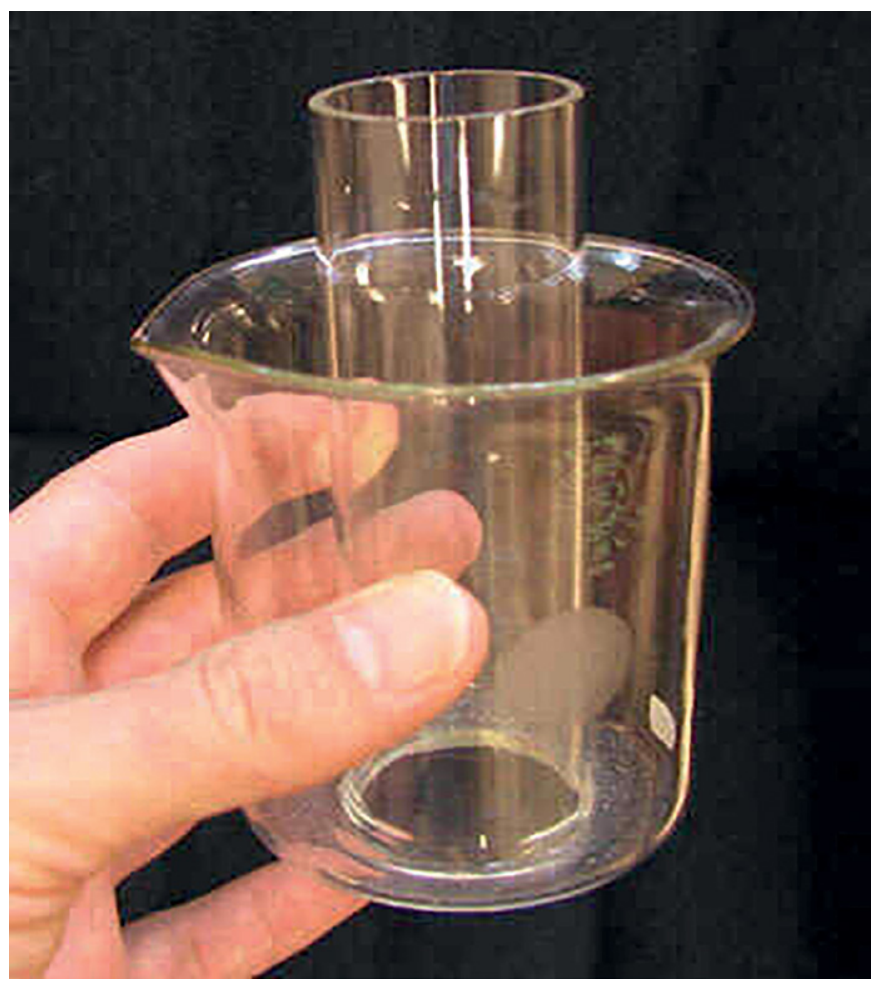

Рисунок 2. Сосуд Маринелли (оригинальная версия).

В середине - конце 1950-х гг. начали появляться жидкостные сцинтилляционные счетчики. Вследствие этого сцинтилляционный метод регистрации (наиболее распространенными сцинтилляторами являются кристаллы йодистого натрия, Nal) стал широко доступен. В это время основной вариант анализа образцов был с использованием сосудов Маринелли, кольцевых трубок ГейгераМюллера и погружающихся трубок Гейгера-Мюллера (рис. 3).

Следует отметить, что сосуды Маринелли могли вместить большее количество образца, чем кольцевые счетчики Гейгера-Мюллера, следовательно, они являлись более эффективными для измерений гамма-излучения. В противоположность этому, для подсчета бета-частиц они были менее результативны, чем кольцевые трубки, так как бета-частицы должны были проникать через

Original version of Marinelli beaker

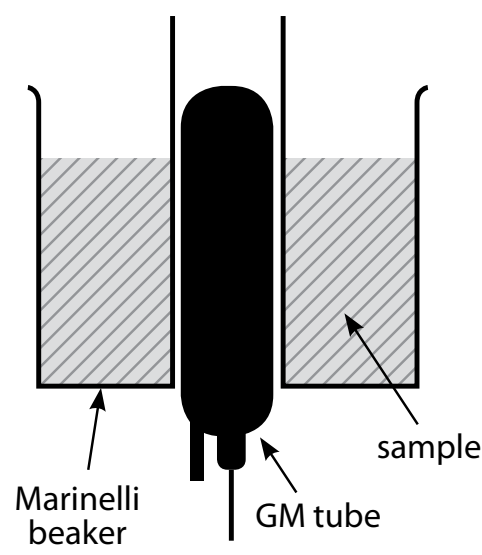

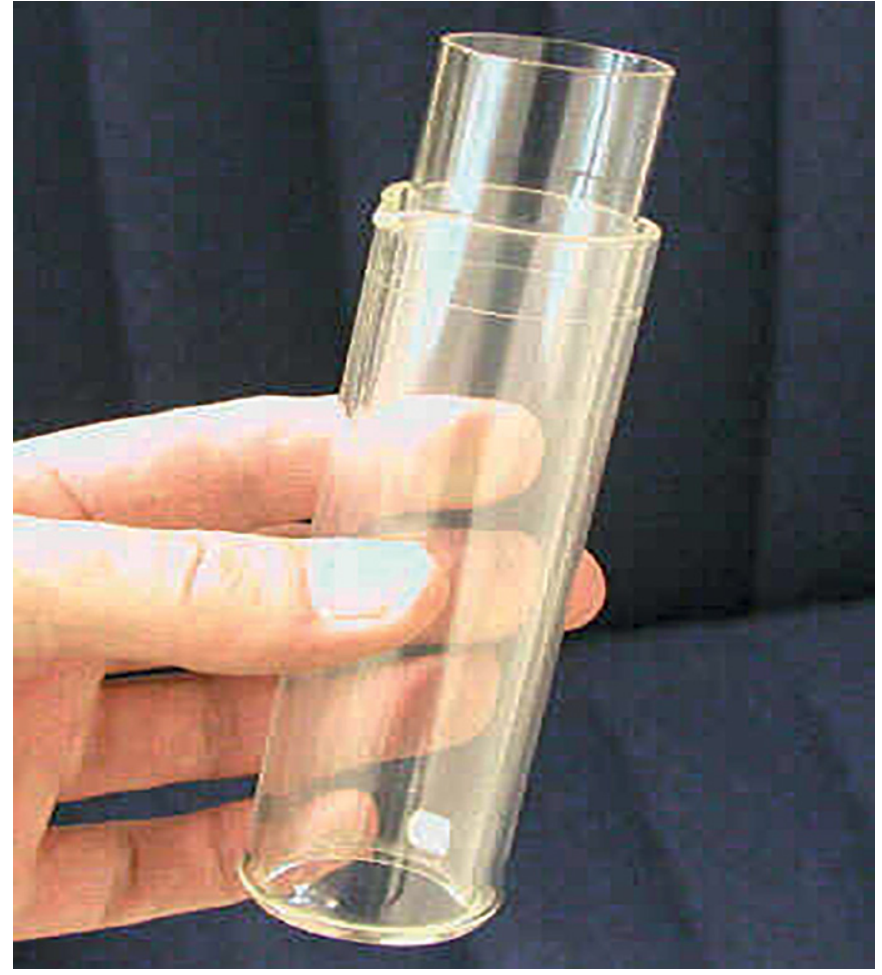

Рисунок 3. Сосуды Маринелли (лабораторный вариант).

оболочку сосуда, а также в стенку детектора. Одним из наиболее существенных недостатков использования кольцевых детекторов является сложность их очистки при работе с долгоживущими радионуклидами.

Альтернативный способ анализа образца заключается в его сушке и подсчете с помощью описанного выше детектора или электроскопа (например, Landsverk Model L-75). Разумеется, что данный способ было сложно осуществить, а также был риск появления неточности из-за испарения йода [8].

По мере того, как сцинтилляторы Nal становились наиболее популярными, ученые решили применять тот контейнер для образцов, который сегодня известен как сосуд Маринелли (рис. 4): достаточно большой пластмассовый стакан с кольцевым дном, которое передвигалось по кристаллу Nal [9].

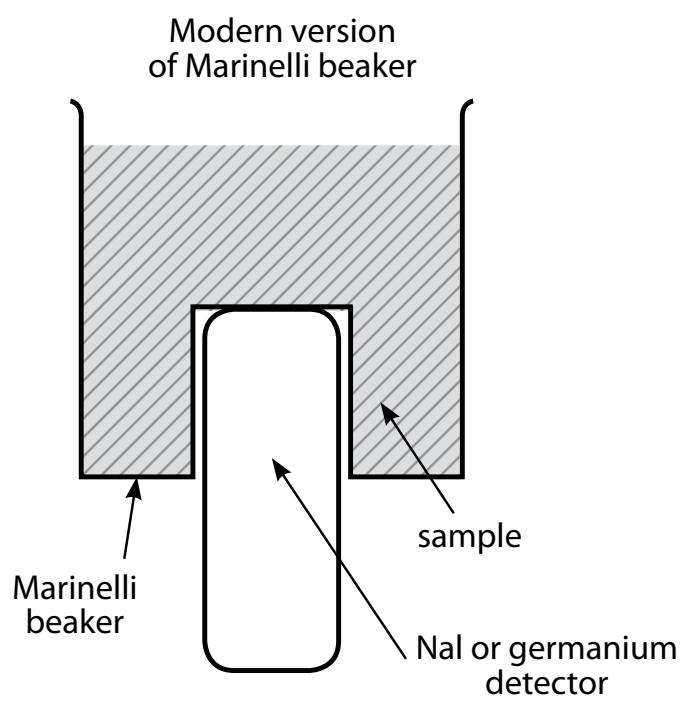


В феврале 1942 г. он опубликовал теоретические основы дозиметрии внутреннего облучения, которые легли в основу ядерной медицины и радиобиологии. В 1946 г. ученый опубликовал работу по применению радиоактивного лечения функционального рака щитовидной железы. За этим прорывом последовали методики авторадиографии и отчет по обзору современной физики о бета-лучах. Популярность ядерной медицины расширила его обязанности в качестве главы отдела физики в Мемориал Слоан Кеттеринг институте. В 1948 г. он добавил к своей публикации дозиметрии внутреннего облучения дополнительные биологические соображения, представленные Эдит Куимби.

В 1948 г. Леонидас Д. Маринелли переехал в Аргоннскую национальную лабораторию, здесь он был назначен на должность на факультете Чикагского университета, где продолжил свою карьеру и с Джоном Э. Роузом взял научное руководство Отделением радиологической физики и одновременно Отделом биологических и медицинских исследований.

\section{ФОРМУЛА МАРИНЕЛЛИ}

Нельзя не сказать о совместной работе Э. Куимби и Л. Маринелли, проделанной в 1948 г. Эти медицинские физики были первыми, кто попробовал оптимизировать лечение с использованием радиоактивных веществ. Основой их методики является использование дозиметрических методов расчета внутреннего облучения равномерно распределенными источниками ${ }^{226} \mathrm{Ra}$. Данный радиофармпрепарат использовался как эталонный источник для получения коэффициента модели 25. Для лечения заболеваний щитовидной железы ${ }^{226} \mathrm{Ra}$ не применяется. В своих расчетах ученые делали допущение, что энергия бета-частиц ${ }^{131}$ І поглощается в местах их рождения. По мнению медицинских физиков, особое место при вычислении терапевтической активности (А) ${ }^{131}$ I занимали этапы исследования фармакокинетики и физико-математическое моделирование распределения частиц в организме. Учитывая вышеперечисленные факторы, была предложена довольно простая формула для расчета:

$$
A=\frac{25 \times m \times D}{U_{244} \times T_{\text {eff }}} ;
$$

где $\mathrm{T}_{\text {eff }}$ - эффективное время полувыведения ${ }^{131} \mathrm{I}$, с; $\mathrm{m}$ - масса щитовидной железы от 24-го к 48-му часу происходящего процесса, г;

$U_{244}$ - процентное содержание захваченных частиц ${ }^{131}$ I на 24-й час после введения препарата, \%;

25 - конверсионный коэффициент между активностью и дозой D, Гр, учитывающий среднюю энергию бетачастиц ${ }^{131}$ I [10].

Главное преимущество использования данной формулы заключается в учете экспоненциального уменьшения изотопа в мишени и массы самой мишени, однако есть и существенные недостатки - в вычислениях учитывается среднее значение энергии частиц и расчет требует длительного периода наблюдения для определения эффективного времени полувыведения ${ }^{131}$ | из щитовидной железы.

Также они стали основоположниками принципа ALARA (As Low As Reasonably Achievable), который был сформулирован в 1954 г. Международной Комиссией по Радиологической защите. Данный принцип заключался в минимизации воздействия ионизирующего излучения [11].

\section{РЕЗУЛЬТАТЫ ЖИЗНЕННОГО ПУТИ}

Леонидас Д. Маринелли вышел на пенсию в 1971 г., проработав пять лет директором Отдела радиологической физики. Маринелли был членом или консультантом более 30 комитетов, подкомитетов и международных комиссий по исследованию некоторых аспектов облучения, от фундаментальных единиц до биологического взаимодействия.

Он принимал активное участие в работе Радиологического общества Северной Америки, Международной комиссии по радиационной защите («Комитет по допустимой дозе», the International Commission on Radiation Protection), Консультативного комитета Комиссии по атомной энергии («Биология и медицина»), Журнале Правления по физике здоровья, Всемирной организации здравоохранения («Экспертно-консультативная группа по радиации»), нескольких учреждениях Службы общественного здравоохранения США и многих других организации.

Маринелли опубликовал свой 100-й и последний документ в 1974 г., за несколько месяцев до смерти. Его коллега доктор Р. Майкл Фрай прокомментировал: «Возможно, это статья, в которой можно кратко описать работу его жизни, сконцентрированной на исследованиях, связанных с риском развития рака». В статье оцениваются методы, предложенные другими учеными, и за семь шагов читатель приходит к выводу, что не существует такой внутренней радиоактивности, которая могла бы гарантировать, что в дальнейшем не будет обязательных последствий [12].

Жизненный путь этого гениального ученого сам по себе является невероятным феноменом: 19-летний молодой человек без средств эмигрировал из Италии в США, начал свою деятельность с должности лаборанта в электротехническом колледже и 40 лет спустя стал одним из самых авторитетных членов Международного совета сотрудников Minerva Nucleare, журнала Итальянского общества радиологии и ядерной медицины, внес огромный вклад в современную медицину в целом. Маринелли обладал способностью объединять и сплетать результаты и выводы других ученых и внедрять свои собственные инновационные экспериментальные методы с научной строгостью и точностью.

Леонидас Маринелли был не только великим исследователем, но и любящим и заботливым семьянином. Дочь ученого, Джудит Маринелли Годфри, в своей рукописи, посвященной отцу, отмечает, что он был предан своей семье, своей жене Елене Акампора и дочерям Джудит и Амелии Линда. Своим бесконечным любопытством к жизни он вдохновлял своих близких с интересом смотреть вокруг и верить в историческую перспективу своих открытий.

Природа щедро одарила Маринелли жизненными силами и здоровьем духа, но затем позволила им истощиться, ознаменовав ранним появлением проблем со здоровьем. Таким образом, тень грусти и беспокойства пришлась на последние годы ученого, к великой скорби 
всех тех, кто был благословлен теплотой дружбы с этим невероятным человеком. Маринелли ушел из жизни 13 сентября 1974 г. в возрасте 67 лет в городе Хинсдейл, округ Дюпейдж, штат Иллинойс.

Следует отметить, что Маринелли является автором некоторых статей из сборника по дозиметрии: Annual Review of Nuclear Science, Radiation Biology, Handbook of Medical Radiology. В области радиологии ученый является одним из первых, кто обнаружил, какое влияние оказывает радиоактивность на человека, изучив, как радиоактивные вещества распределяются в тканях. Благодаря его усилиям, появился Центр радиобиологии человека, который на данный момент несет ответственность за все исследования по воздействию радиоизотопов, введенных внутрь организма, поддерживаемые комиссией по атомной энергии.

Маринелли-Роуд в Роквилле, штат Мэриленд назван в честь Леонидаса Д. Маринелли, а также место, где расположен американский офис штаба Комиссии по ядерному регулированию.

\section{ЗАКЛЮЧЕНИЕ}

Леонидас Д. Маринелли является величайшим американским физиком-радиологом с итальянскими корнями. Удивительно, что человек, несмотря на то, что не был связан с медициной напрямую, смог реализовать свое желание помогать людям в наивысшей степени. Благодаря его усилиям, жизненному труду и стремлениям мы имеем представление о влиянии радиации на организм, широкие диагностические и терапевтические возможности, огромное количество спасенных жизней не одного поколения, вектор развития медицины и около медицинских направлений науки.

\section{ДОПОЛНИТЕЛЬНАЯ ИНФОРМАЦИЯ}

Источник финансирования. Отсутствует.

Конфликт интересов. Авторы декларируют отсутствие явных и потенциальных конфликтов интересов, связанных с публикацией настоящей статьи.

\section{СПИСОК ЛИТЕРАТУРЫ | REFERENCES}

\footnotetext{
1. Available at: https://en.wikipedia.org/wiki/Leonidas_D._Marinelli

2. Brucer M. Leonidas D. Marinelli, Ph.D. Radiology. 1975;115(2):488-489. doi: https://doi.org/10.1148/115.2.488

3. Available at: https://infogalactic.com/info/Leonidas_D. Marinelli

4. Румянцев П.О., Коренев С.В.История появления терапии радиоактивным йодом // Клиническая и экспериментальная миреоидология. - 2015. - Т. 11. — №4. - С. 51-55.

[Rumiantsev PO, Korenev SV. The history of radioiodine therapy beginnings. Clinical and experimental thyroidology. 2015;11(4):51-55. (In Russ.)]. doi: https://doi.org/10.14341/ket2015451-55

5. Fano U. Leonidas D. Marinelli (1906-1974). Radiat Res. 1975;61(3):538-539. doi: https://doi.org/10.2307/3574129
}

6. Available at: https://www.orau.org/ptp/collection/Miscellaneous/ marinelli.htm

7. Marinelli LD, Hill RF. In Brookhaven National Laboratory Conference Report BNL-C-5; 1948, 98 p.

8. Bruner, H.D. and Perkinson, J.D. A Comparison of lodine-131 Counting Methods. Nucleonics October 1952, $57 \mathrm{p}$.

9. Dratz, A.F. Well-Bottom Container Improves Gamma Counting Nucleonics August 1957, 83 p.

10. Marinelli LD. Dosage determination in the use of radioactive isotopes. J Clin Invest. 1949;28(6 Pt 1):1271-1280. doi: https://doi.org/10.1172/JCl102194

11. Available at: https://ru.wikipedia.org/wiki/AЛАРА

12. Godfrey JM. Leonidas Marinelli: Pioneer in Radiological Physics. September 2013.

\section{ИНФОРМАЦИЯ ОБ АВТОРАХ [AUTHORS INFO]}

*Юдаков Данила Витальевич [Danila V. Yudakov]; адрес: Россия, 115409, Москва, Каширское ш., д. 31 , [address: 31, Kashirskoe hwy, 115409, Moscow, Russia]; ORCID: 0000-0001-9708-0470; eLibrary SPIN: 9299-6542; e-mail: danila27.03@mail.ru

Бондаренко София Павловна [Sofiia P. Bondarenko]; ORCID: 0000-0003-0259-372X; eLibrary SPIN: 8352-1085; e-mail: sofiyabondrnimu@gmail.com

Трухин Алексей Андреевич [Alexey A. Trukhin]; ORCID: 0000-0001-5592-4727; eLibrary SPIN: 4398-9536; e-mail: alexey.trukhin12@gmail.com

\section{ЦИТИРОВАТЬ:}

Юдаков Д.В., Бондаренко С.П., Трухин А.А. От физики до медицины. Фундаменталист Леонидас Д. Маринелли // Клиническая и экспериментальная тиреоидология. - 2021. - Т. 17. — №4. — С. 21-25.

doi: https://doi.org/10.14341/ket12547

Рукопись получена: 24.07.2020. Одобрена к публикации: 29.11.2021.

\section{TO CITE THIS ARTICLE:}

Yudakov DV, Bondarenko SP, Trukhin AA. From physics to medicine, fundamentalist Leonidas D. Marinelli. Clinical and experimental thyroidology. 2021;17(4):21-25. doi: https://doi.org/10.14341/ket12547

Received: 24.07.2020. Accepted: 29.11.2021. 